\title{
Doctor of Veterinary Medicine
}

National Cancer Institute

\section{Source}

National Cancer Institute. Doctor of Veterinary Medicine. NCI Thesaurus. Code C39391.

The Doctor of Veterinary Medicine degree is a postgraduate first-professional degree awarded for graduates who have completed a program of studies in veterinary medicine. 